\title{
Virtually Uncharted Waters: How a Global Pandemic Has Taken Pre-Service Teachers out of Physical Classrooms and Perpetuated Pre-Identified Gaps in Preparedness for Working With Emergent Bilingual Students
}

\author{
Hannah Meineke \\ Correspondence: Hannah Meineke, 11400 Concordia University Dr, Austin TX 78726, United States.
}

Received: October 12, 2021

Accepted: November 2, 2021

Online Published: November 12, 2021

doi:10.11114/jets.v10i1.5404

URL: https://doi.org/10.11114/jets.v10i1.5404

\begin{abstract}
COVID-19 has changed the way of life for nearly every individual in the US. One of the greatest causes of familial and systematic turmoil has been the transition of K-12 schools to the uncharted waters of remote learning. When COVID-19 forced the termination of practicum placements for pre-service teachers, it also limited the opportunity for pre-service teachers to have in-person exposure to Emergent Bilingual Students (EBS), an essential piece of creating Knowledge, Skills, and Dispositions (KSDs) needed for their future classrooms. In this essay, I look back at research addressing the KSD gaps created through the lack of exposure pre-service teachers have when it comes to working with EBS. Building on previous research related to the KSDs gained from practicum placements with EBS, pre-service teacher gaps are identified, pandemic perpetuation of gaps are put forth, and potential solutions are named.
\end{abstract}

Keywords: emergent bilingual, pre-service preparation, practicum placements, educational opportunity

\section{Pre-Service Teachers and the Pandemic}

COVID-19 has undeniably disrupted systems, professions, and households changing the way of life for nearly every individual in the US. One of the greatest causes of familial and systematic turmoil has been the transition of K-12 schools to the uncharted waters of remote learning (Garcia \& Weiss, 2020). Furthermore, not only has the global pandemic surfaced and re-affirmed pre-existing concerns in schools such as health and safety of students, attendance, teacher safety, and retention it has perpetuated and even escalated the socioeconomic achievement gap (Ladson-Billings, 2006) and digital divide (Iivari, Sharma \&Ventä-Olkkonen, 2020).

Practicum placements are created to prepare pre-service teachers for their future classrooms. These "hands-on" experiences foster awareness and knowledge of many issues including the endemic nature of privilege and oppression essential for closing the achievement gap (Ladson- Billings, 2006; McLaren, 1999). When COVID-19 forced the termination of practicum placements for pre-service teachers it also limited this opportunity (Heineke, Smetana \& Sanei, 2018). Prior to the pandemic, research on pre-service program models revealed that while some pre-service teachers are fully immersed in classrooms with high populations of Emergent Bilingual Students (EBS) from the start of their program, others have very little, if any, exposure to EBS prior to their clinical teaching semester. This difference in clinical exposure leads to variance in enactment of Knowledge, Skills and Dispositions (KSDs) beneficial for teaching EBS (Meineke \& DeVasto, 2020).

\section{Methodology}

The opportunity to measure the impact of the changed nature of practicum placements has only just begun. However, previous research suggests that fieldwork experiences and exposure are essential learning opportunities for pre-service teachers. In this essay, I look back at research addressing the KSD gaps created through the lack of exposure pre-service teachers have when it comes to working with EBS. Building on previous research related to the KSDs gained from practicum placements with EBS, I seek to answer two key uncharted questions: How has COVID-19 prevented the acquisition of the pre-identified KSDs? How can pre-service programs maintain or even enhance EBS learning opportunities despite COVID-19? 


\section{Pre-Service Teacher Preparation: Will They Sink or Swim?}

The word "sink" is often associated with drowning, a helpless feeling of surrendering to a larger power. In the classroom, Emergent Bilingual Students (EBS) are often given the "sink or swim" option when it comes to assimilating to the English-only ideology (Horner, 2001). For beginning teachers, a similar "sink or swim" mentality is often adopted. The Knowledge, Skills, and Dispositions useful for teaching Emergent Bilingual Students are learned through both intentional integration in pre-service coursework and pre-service practicum placements (Meineke \&DeVasto, 2020).

Pre-service preparation brings Knowledge, Skills and Dispositions (KSDs) that serve as a flotation device for meeting the diverse needs of students. Previous research demonstrates the positive, transformational power immersion can have in influencing the KSDs of pre-service teachers (Olson \& Jimenez-Silva, 2009). I have outlined some of the benefits of immersive practicum placements as demonstrated by previous research and ways in which COVID-19 has deepened pre-existing preparation gaps caused by lack of immersion. I have also proposed solutions addressing the already missing pieces in program model preparation. Each pre-service program is unique so each proposed solution may not be possible. However, addressing pre-existing and new EBS preparation gaps by casting a wide net of solutions may catch some pre-service teachers and change the course of action for their future classrooms.

\section{Immersive Benefit: Confidence over Ambivalence}

A program model that immerses students in emergent bilingual experiences brings about a disposition of comfort and confidence for teaching this group. Jimenez-Silvia, Olson \& Jimenez Hernandez (2012) argue that a significant factor in improving the instructional practices for EBS is pre-service teachers' confidence in their ability to teach EBS successfully in the classroom. Although the ambiguous word "confidence" may not seem like an essential KSD for teaching emergent bilinguals, without it, a negative disposition of ambivalence may occur. Previous research suggests this ambivalence may come from the belief that EBS are not the responsibility of general education students (Reeves, 2006).

\section{Pandemic Perpetuation: Waves of Ambivalence}

Many pre-service teachers lack experiences in diverse school settings when they begin teacher preparation programs (Hutchinson, 2013). During the pandemic, departments of public instruction and teacher education agencies relaxed fieldwork and clinical teaching requirements which kept pre-service teachers well and out of physical K-12 classrooms (Wisconsin Department of Public Instruction; Texas Education Agency, 2020). In meeting minimum requirements remedied by less effective virtual experiences and videos, pre-service teachers are not able to interact directly with EBS and, therefore, miss out on opportunities to shift ambivalence to asset-based thinking. Without exposure and experiences, the perpetuation of the cyclic nature of education (McLaren, 1999) implicitly pushes pre-service teachers to participate in the ever-present dominant ideology cycle. When pre-service teachers are unable to see past English fluency as the sole need for emergent bilinguals, the cycle continues as "students are led to believe their linguistic success is a priority in bilingual and ESL education, when, in fact, untrained teachers, a lack of culturally relevant curriculum, and underfunded programs continue to contribute to the lack of success and dehumanization of linguistic and cultural values of those groups" (Bordan, 2014, p.230).

\section{Proposed Solution for Waves of Ambivalence}

Across the country, certification agencies have allowed pre-service programs flexibility when it comes to the number of hours pre-service teachers are required to log in K-12 classrooms. This increased level of certification autonomy along with virtual access to classrooms that were geographically unavailable in pre-COVID times, increases the ability of pre-service programs to pivot toward partnerships with more linguistically diverse populations. Those program chairs, education faculty, and others directing practicum placements may use this as an opportunity to build connections with new schools and districts.

Additionally, many pre-service teachers have reported feeling low confidence from their virtual placements because of an inability to connect with students (Varea \& Gonzalez-Calvo, 2020). Given a decreased restriction in hourly requirements from certification agencies, pre-service programs can "make up the difference" by connecting pre-service students to EBS through programs outside of the traditional classrooms. For example, in Dallas and Austin Texas an organization called Academy Four provides mentors for all fourth-grade students in disadvantaged schools (Academy Four, 2020). The program intimately and virtually connects mentors with linguistically diverse students. Flexibility in required fieldwork hour settings may allow for pre-service access to EBS and help shift pre-existing ambivalent mindsets.

\section{Immersive Benefit: A Teacher for All Students}

Some research suggests this ambivalence can/may be overcome through exposure leading to a broader understanding of students. Yoon, B.(2008) uses positioning theory to analyze interviews and observations centralized around teachers' beliefs about Emergent Bilingual Students (EBS), their teaching practices toward EBS and the EBS participatory behaviors. The findings indicated that the teachers' approaches were grounded in their positioning of themselves as 
teachers for all students, some students, or a single student. Emergent Bilingual Students were more interactive when the teachers showed an understanding of, and actively responded to, their cultural and social needs.

\section{Pandemic Perpetuation: A Teacher for Some Students}

Gonzales (2012) discusses how support for linguistic and cultural needs calls for a change in mindset: an adjustment in attitudes, beliefs, and biases around emergent bilingual students. This shift from assimilative perspectives to progressive and pluralistic ideologies serves as an anchor in the design of preparation programs, as ideology grips and holds together the KSDs developed by pre-service teachers when pivotal moments occur. The year of the pandemic has also been a year of shedding light on the racial and cultural tensions present in our society. Public institutions are microcosms of society. As such, they mirror the policies and ideologies of society; a notion that contributes to the cyclic nature of education and the width between the privileged and oppressed. Although Institutions of Higher Education and pre-service programs are feeling the need to incorporate these critical racial and cultural conversations in their coursework (McKenzie, 2020), the limited ability to connect coursework to the K-12 classroom dilutes the pivotal discussions and reflection. This connection of practicum placements to coursework plays a central role in creating meaningful immersion and pre-service teacher selfpositioning. Without meaningful immersion, preconceived pre-service beliefs, perceptions, and attitudes toward EBS will remain steadfast.

\section{Proposed Solution for A Teacher for Some Students}

Events of 2020 surfaced and magnified deep, systemic racial injustices and tension at both the individual and institutional level. Universities were compelled to update policies (McKenzie, 2020) thereby opening the door for updating curricula and implementing both formal and informal discussions related to oppression and privilege. These types of discussions, especially ones related to language oppression, should also be intentionally integrated into pre-service curricula. Previous research addresses a necessity for the implicit building of cultural competence not only through emergent bilingual exposure but also through reflection and discussion following that exposure (He, 2013). Recent current events create an opportunity for students to reflect on what they are being exposed to in their daily lives with what they are learning in their coursework, even if traditional classroom EBS exposure is limited. This connection of current events to classroom learning can begin through critical conversation and be reinforced through reflection journals. Reflection journals (de Oliveira, and Shoffner, 2009) may not be a specific emergent bilingual technique, but the ability for pre-service teachers to use reflection as a tool for growth in their KSDs related to diverse learners and cultures, current events, and critical conversations, is in fact a methodological strategy for mitigating this pandemic perpetuation.

\section{Immersive Benefit: The Assets of Home Language and Home Culture}

Consciously or subconsciously, mainstream society uses language to form views and opinions of people (Kincheloe, McLaren, \& Steinberg, 2011). Language subjectivity directly connects to how teachers view the linguistically diverse students in their classrooms; and whether they approach the home language as a problem, a privilege, or a right. Pre-service teachers exposed to the notion of language subjectivity have a better grasp on the Knowledge, Skills and Dispositions (KSDs) that value home language (Meineke \& Devasto, 2020). Hutchinson, M. (2013) conducted a study that exposed pre-service teachers to practicum placements with EBS students and measured their changes in perception. Data revealed increased acknowledgment of pre-service teachers regarding the benefit of native-language instruction used to scaffold learning for EBS. Until personal connections are made, it is easy to see home language as a problem rather than a right and an asset in the classroom.

\section{Pandemic Perpetuation: Seeing English Only}

Assimilation - as a process of cultural and language acquisition - is not linear. In fact, there are many models of assimilation, some more cyclical than others, when viewed from a critical perspective. This variance is because each is not without subjectivity, and reproduces class, race, language, and gender oppression (Kincheloe, McLaren, \& Steinberg, 2011). Because of the historical value placed on assimilation and mainstream American customs, along with the customs and values of American subcultures, the linguistic outcome of English monolingualism continues to be a typology adopted by EBS (Linton, 2004). In preparing teachers for this environment, it is important to acknowledge how monolingualism may be embedded into pre-existing ideology or into K-12 classrooms. Without the ability to physically be in classrooms and examine the walls, the books, the projects and without the ability to speak candidly with cooperating teachers unburdened by the technological and time time-consuming demands of the pandemic, monolingualism conversations in the pre-service classroom will lack depth and dimension. Proximity to EBS allows pre-service teachers to navigate toward care. Care for home language and culture, care for individual identities, and care for asset-based thinking. Distance from EBS directs students toward mainstream societal influences of fear of the other and the privileging of monolingualism. Mainstream views of languages other than English and fear of cultural differences are guided by a longstanding lighthouse of fear. 


\section{Proposed Solution for Seeing English Only}

Pre-service teachers exposed to the notion of language subjectivity are likely have a better grasp on the Knowledge, Skills and Dispositions (KSDs) that value home language (Meineke \&DeVasto, 2020). Attendance at an Institution of Higher Education (IHE) during the pandemic is significantly different than attendance prior to the pandemic. Experiences outside of classes are limited or virtual. The restricted social experience unintentionally keeps students at IHE from implicitly learning from others. Absorbing and learning the home cultures and hearing the home language of fellow students through time together in social settings is largely absent. Deficient social experiences or lack of socialization increases the importance of integrating the notion of language subjectivity into pre-service coursework. Beyond the explicit discussions, professors should consider their treatment and emphasis of the unique languages and cultures of their pre-service teachers. Empowering relationships can be found where autonomy, creativity, self-improvement, and consistency in coursework are found (Nichols \& Zahng, 2011). In the teaching and learning relationship, K12 students can be given power when pre-service teachers have power to give. Modeling the value of pre-service teacher home language and home culture can empower them to do the same in their classrooms. Creating coursework that asks students to learn about and from one another can open up otherwise restricted interactions.

\section{Conclusion}

Knowledge, Skills, and Dispositions (KSDs) found in coursework models are not an isolated product, but rather the result of many voices and powers. These influences shape the learning opportunities, coursework, and practicum placements of preservice teachers. Additionally, all preservice coursework models are subject to the pressures of time, enrollment, and policy, which have the ability to transform or perpetuate structures that marginalize Emergent Bilingual Students (EBS). Previous research highlights the importance of EBS exposure for pre-service teachers in gaining KSDs useful for their future classrooms. The onset of COVID-19 has decreased in-person classroom observations and field work which has also decreased potential in gaining necessary KSDs. The field of education mirrors both societal structures and cultural changes (McLaren, 1999). It is critical that in 2021, pre-service programs shift priorities and look to changing policies dedicated to marginalized groups rather than perpetuating pre-identified pre-service preparation gaps. Future research may explore effective virtual connections with EBS-serving classrooms; the value of intentional reflections, activities, and discussions around language subjectivity integrated into pre-service coursework; the power of empowering pre-service teachers in the university classroom by modeling the value of home language and home culture. It is my hope that this essay highlights the relevance of EBS exposure in pre-service teacher coursework and offers potential solutions that compensate for the lack of in-person observations and field work due to COVID-19.

\section{References}

Borden, R. S. (2014). The English Only Movement: Revisiting Cultural Hegemony. Multicultural Perspectives, 16, 229-233. https://doi.org/10.1080/15210960.2014.956607

De Oliverira, L., \& Shoffner, M. (2009). Addressing the needs of English language learners in an English education methods course. English Education, 42(1), 91-111.

Edtpa covid-19. (2020, April 03). Retrieved February 12, 2021, from https://dpi.wi.gov/licensing/edtpa-covid19

Garcia, E., \& Weiss, E. (2020, September 10). COVID-19 and student performance, equity, and U.S. EDUCATION policy: Lessons From PRE-PANDEMIC research to inform RELIEF, recovery, and rebuilding. Retrieved February 12, 2021, from

https://www.epi.org/publication/the-consequences-of-the-covid-19-pandemic-for-education-performance-and-equit y-in-the-united-states-what-can-we-learn-from-pre-pandemic-research-to-inform-relief-recovery-and-rebuilding/

Gonzalez, V. (2012). Assessment of bilingual/multilingual pre-k-grade 12 students: A critical discussion of past, present, and future issues. Theory into Practice, 51(4), 290-296. https://doi.org/10.1080/00405841.2012.726058

Guidance on Educator Certification and Preparation Candidates Completing Programs in the 2019-2020 Academic Year. (2020, August 10). Retrieved February 12, 2021, from

https://tea.texas.gov/sites/default/files/covid/covid19-educator-certification-and preparation-guidance-faq.pdfHe, Y. (2013). Developing teachers' cultural competence: application of appreciative inquiry in ESL teacher education. Teacher Development, 17(1), 55-71. https://doi.org/10.1080/13664530.2012.753944

Heineke, A., Smetana, L., \& Carlson, S. J. (2019). A Qualitative Case Study of Field-Based Teacher Education: One Candidate's Evolving Expertise of Science Teaching for Emergent Bilinguals. Journal of Science Teacher Education, 30(1), 80-100. https://doi.org/10.1080/1046560X.2018.1537058

Horner, B. (2001). "Students' right,"English only, and re-imagining the politics of language. College English, 63(6), 741-758. https://doi.org/10.2307/1350100 
Hutchinson, M. (2013). Bridging the gap: Preservice teachers and their knowledge of working with English language learners. TESOL, 4(1), 25-54. https://doi.org/10.1002/tesj.51

Ivari, N., Sharma, S., \& Ventä-Olkkonen, L. (2020). Digital transformation of everyday life - How COVID-19 pandemic transformed the basic education of the young generation and why information management research should care? International Journal of Information Management. 55(1), 1-5. https://doi.org/10.1016/j.ijinfomgt.2020.102183

Jimenez-Silvia, M., Olson, K., \& Jimenez, H. N. (2012). The confidence to teach English language learners: exploring coursework's role in developing preservice teachers' efficacy. The Teacher Educator, 47, 9-28. https://doi.org/10.1080/08878730.2011.632471

Kincheloe, J., McLaren, P., \& Steinberg, S. (2011). The Sage Handbook of Qualitative Research $\left(4^{\text {th }}\right.$ ed). Thousand Oaks, CA: Sage Publications.

Ladson-Billings, G. (2006). From the Achievement Gap to the Education Debt: Understanding Achievement in U.S. Schools. Educational Researcher, 35(7), 3-12. https://doi.org/10.3102/0013189X035007003

Linton, A. (2004). A Critical Mass Model of Bilingualism among U.S.-Born Hispanics. The University of North Carolina Press, 83(1), 279-314. https://doi.org/10.1353/sof.2004.0119

McKenzie, L. (2020, October 22). Adding ethnic studies into college curricula has long been controversial, but is this moment different? Retrieved February 12, 2021, from https://www.insidehighered.com/news/2020/10/22/adding-ethnic-studies-collegecurricula-has-long-been-controver sial-moment-different

McLaren, P. (1999). A Pedagogy of Possibility: Reflecting upon Paulo Freire's Politics of Education: In Memory of Paulo Freire. Educational Researcher, 28(2), 49-54. https://doi.org/10.2307/1177189

Meineke, H., \& DeVasto, D. (2020). The Subject of Subjectivity: Preparing Teachers with the Knowledge, Skills, and Dispositions Needed for Empowering Emergent Bilingual Students. Journal of Teacher Education and Educators, 9(1), 61-82.

MENTOR a 4th GRADER. (n.d.). Retrieved February 12, 2021, from https://academy4.org/change-lives-mentor

Nichols, J., \& Zhang, G. (2011). Classroom environment and student empowerment: an analysis of elementary and secondary teacher beliefs. Learning Environments Research, 14(3), 229-239. https://doi.org/10.1007/s10984-011-9091-1

Olson, K., \& Jimenez-Silva, M. (2009). The campfire effect: a preliminary analysis of preservice teachers' beliefs about teaching English language learners after state-mandated endorsement courses. Journal of Research in Childhood Education, 23(3), 246-260. https://doi.org/10.1080/02568540809594625

Reeves, J. R. (2006). Secondary teacher attitudes toward including english-language learners in mainstream classrooms. Journal of Educational Research, 99(3), 131-142. https://doi.org/10.3200/JOER.99.3.131-143

Varea, V., González-Calvo, G., \& García-Monge, A. (2020) Exploring the changes of physical education in the age of Covid-19. Physical Education \& Sport Pedagogy, O(0), 1-11. https://doi.org/10.1080/17408989.2020.1861233

Yoon, T. (2013) Listening to ESL students' real voice: A case study of multicultural English Language Arts (ELA) classroom. International Journal of Research Studies in Education, 2(3), 75-83.

https://doi.org/10.5861/ijrse.2012.230

\section{Copyrights}

Copyright for this article is retained by the author(s), with first publication rights granted to the journal.

This is an open-access article distributed under the terms and conditions of the Creative Commons Attribution license which permits unrestricted use, distribution, and reproduction in any medium, provided the original work is properly cited. 